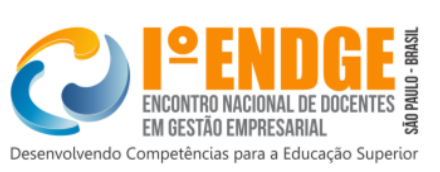

Área Temática: Gestão Financeira

\title{
A Engenharia de Custos Procedural: tecnologia para neurogestão da produção de serviços hospitalares
}

Otavino Alves da Silva - otavino@uol.com.br

Universidade do Estado de Minas Gerais-UEM

\begin{abstract}
Resumo
O Ministério da Saúde instituiu, em 2006, o Programa Nacional de Gestão de Custos (PNGC) e, posteriormente, o sistema Apurasus para adoção pelos hospitais conveniados com o SUS como estímulo para melhoria do seu processo de tomada de decisão. Sabe-se que pouquíssimos hospitais aderiram à novidade. Duas pesquisas a respeito da implantação do PNGC mostram seu insucesso por várias razões. Diante desses eventos, pensou-se, neste trabalho, apresentar para discussão sobre o emprego da Engenharia de Custos Procedural, uma tecnologia inovadora e revolucionária desenhada com base nos princípios e postulados do Business Model Generation (CANVAS) e do Design Thinking, como ferramentas de neurogestão de uma unidade de prática integrada (UPI), compatibilizando aquela tecnologia com a metodologia Backward Analysis. Recomenda-se, ao final, o estudo avançar na definição de estratégias matemáticas para mensuração os custos como aportes de capital e validação de seus resultados: o melhor custo para uma unidade hospitalar.
\end{abstract}

Palavras-chave: gestão, engenharia de custos, procedural

\begin{abstract}
In 2006, the Ministry of Health established the National Program of Cost Management (PNGC in Portuguese) and subsequently the Apurasus system for hospitals affiliated with the SUS in order to improve their decision-making process. It is known that few hospitals have joined to these systems. Two surveys about PNGC implementation show that its failure for several reasons. Regarding these events, this work present the Procedural Cost Engineering, an innovative and revolutionary technology designed based on the principles and postulates of Business Model Generation (CANVAS) and Design Thinking, that can be used as neurological management tools to drive integrated practice unit (IPU), aligning with Backward Analysis methodology. It is recommended that this study progresses in the definition of mathematical strategies to measure the costs as capital contributions and validation of the results: the best cost for a hospital.
\end{abstract}

Key words: management, cost engineering, procedural 


\section{Introdução}

De Rocchi ( 2014) discute em seu artigo uma afirmação de autoria de Leone \& Leone ( 2007) que diz: "Os engenheiros geram custos, e os contadores os gerem" e que tal afirmação foi confirmada por George Sebastião Guerra Leone em palestra de abertura do XIV Congresso Brasileiro de Custos, em 5 de dezembro de 2007, em João Pessoa (PB). Três comentários, pelo menos, sobre essa afirmação podem ser feitos. Um considerando que os engenheiros ao implementar seu Planejamento e Controle de Produção (PCP) o fazem ineficientemente gerando desperdícios, perdas. Um segundo comentário considerando explícita a tendência de Leone sobrevalorizar a atuação do Contador. E o terceiro comentário considerando que os engenheiros, em sua atuação de converter recursos produtivos em produtos e serviços, respondem pela medida do consumo dos insumos necessários à produção gerando, assim, os custos de produção.

Leone \& Leone (2007: 186) também afirmam que " Reduzir custo significa, na verdade, reduzir e controlar o uso dos recursos mais dispendiosos, sendo que alguns são mais visíveis que outros. Os administradores usam os recursos e sabem quanto custam. Sabem como são consumidos. Por isso, têm a obrigação de controlar suas operações e, consequentemente, analisar os desvios no consumo dos recursos", posto que " os custos são reflexos de ações e decisões tomadas pela gerência dos diversos setores" (idem p.19).

A propósito, em 2006, o Ministério da Saúde (MS) tornou público o Programa Nacional de Gestão de Custos(PNGC), como manual técnico de custos, conceitos e metodologia, desenvolvido no âmbito do Núcleo Nacional de Economia da Saúde (Nunes), vinculado ao Departamento de Economia da Saúde (DES), da Secretaria de Ciência, Tecnologia e Insumos Estratégicos (SCTIE) e posteriormente instituiu a ferramenta informatizada Apurasus ( Sistema de Apuração de Custos e Gestão de Custos do SUS), para emprego pelos hospitais públicos e hospitais conveniados com o SUS.

Como justificativas para implantação do PNGC foram destacadas: a necessidade de conhecer os custos dos produtos e serviços; a necessidade de apurar e avaliar resultados; a contribuição para aprimorar a gestão de custos como vantagem competitiva e parte das ações estratégicas, pois “ as instituições de saúde no Brasil, principalmente as públicas, são as mais distantes no processo de modernização gerencial" e que a maioria delas utiliza métodos contábeis tradicionais, não fazendo uso de sistema de custo que oriente e forneça parâmetro para decisões e controle. O Nunes/DES/SCTIE/MS comprovou, pesquisando 175 hospitais, quantidade significativa deles utilizavam o método de custeio por absorção.

Os poucos hospitais que buscaram implementar o PNGC não obtiveram sucesso em razão de resistência por parte de governanças, dificuldades para fazer ajustes de adequação ao modelo de custeio por absorção recíproca, grande diversidade de especializações médicas o que gera a necessidade de grande número de centros de custos, tendência de fazer tudo para todos. Que modelo de estrutura taxonômica em custos e técnicas para sua alocação poderiam alinhar governança e ajustes para o sucesso da implantação do PNGC?

Como desafio para idear um novo conceito e uma nova tecnologia metodológica para apuração e gestão de custos em unidades hospitalares, neste trabalho será delineada a tecnologia Engenharia de Custos Procedural que se fundamenta nos princípios da Neurogestão e nas técnicas do Business Model Generation ( Canvas), do Design Thinking e na estrutura organizacional da "unidade de prática integrada", desenvolvida por Porter e Teisberg ( 2007), além de normas estabelecidas pela ABNT e Anvisa. 


\section{Revisão Bibliográfica}

A engenharia de custos é um conteúdo mais abordado pelas organizações associadas à construção civil, como o Instituto Brasileiro de Engenharia de Custos (IBEC), vinculado ao Conselho Internacional de Engenharia de Custos (ICEC), e a Editora PINI que editou o livro de Carvalho e Pini (2012). Na área da saúde, há vários artigos publicados alguns deles referenciados ao final do texto, bem como o livro de Porter e Teisberg (2007) que trata da estrutura organizativa "unidade de prática integrada" e o livro de Bertó e Bulke (2012) que fundamenta a metodologia contábil do PNGC.

\section{Metodologia}

Primeiramente, será realizada uma breve apreciação sobre o PNGC que será convenientemente referenciado ao final deste trabalho. Em seguida serão abordados: 1) os conceitos de engenharias e engenharia de custos, de gestão de ativos e gestão de custos cujos autores estarão referenciados; 2) a aplicabilidade da estrutura organizacional conhecida como "unidade de prática integrada" para hospitais, referenciada em Porter e Teisberg, ao final do texto; 3) a usabilidade das técnicas do Canvas e do Design Thinking para justificar a nova estrutura organizacional de pertinência de governança para a engenharia de custos procedural; 4) será apresentada a taxonomia de custos (como aportes de capital), a definição de engenharia de custos procedural e sua respectiva estratégia matemática para construção e sensibilização dos aportes de capital como medida de consumo de recursos produtivos; e 5) por fim, será explicitada a necessidade do emprego da neurogestão como ferramenta para tomada de decisão e efetividade de mudanças.

\section{Análise dos Resultados}

No PNGC, quando da sua institucionalização, admitia "para que a implantação do sistema de custos seja um instrumento gerencial entre as instituições de saúde, é necessário, principalmente, homogeneizar conceitos, normas e rotinas".

Como metodologia, o PNGC adota o sistema de custeio por absorção baseada na alocação recíproca e para homogeneização é adotada a estrutura de centros de custos (administrativos, intermediários, finais ou produtivos), justificando tais adoções " por ser de fácil aplicação e por ser a mais utilizada entre as instituições vinculadas ao SUS", embora seja reconhecido que "o custeio por absorção não fornece informações lapidadas, por isso é difícil identificar as causas dos custos de cada produto/serviço, o que pode levar os tomadores de decisões a considerarem os custos altos e a adotarem cortes dos custos indiretos de forma generalizada" (...) Assim, fica evidente que a informação financeira gerada pelo sistema de custeio por absorção não fornece aos tomadores de decisão uma visão clara da evolução dos custos em relação ao volume de produção das atividades".

Dois estudos de pesquisa em hospitais revelam insucesso na implantação do PNGC e do Apurasus: o do Instituto Nacional do Câncer ( INCA) demonstrado por Teixeira ( 2013) principalmente com respeito aos problemas para fazer os ajustes necessários para estruturação dos centros de custos e a adequação dos controles contábeis à definição da estrutura dos grupos de gastos, na modelagem do PNGC/MS; o outro é relatado por Magalhães a respeito da 


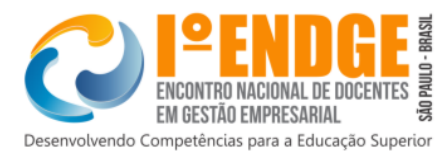

experiência de implantação e uso do sistema Apurasus no Hospital de Base do Distrito Federal. Os maiores gargalos destacados são: separar a carga horária por centro de custo, ajustar o sistema da folha e pagamento, a institucionalização do envio de dados e informações no prazo exigido, rede de Internet ruim, rotatividade do pessoal do Núcleo de Processamento, falta de colaboração de encarregados dos centros de custos, informações sem clareza, contratos sem detalhamento de gastos.

Martins, Portulhak e Voese fizeram uma pesquisa sobre a prática da gestão de custos em hospitais universitários federais, num universo de 34 deles e concluíram que a utilização de sistemas de apuração de custos e gestão de custos efetivamente não está difundida e que tal cenário deve manter-se a curto prazo.

Abbas e outros (2015) desenvolveram uma pesquisa para comparar se havia convergência entre os métodos de custeio praticados por hospitais (14 de 49, de médio e grande porte no Estado do Paraná) e as recomendações acadêmicas apresentadas em seminários nacionais de Contabilidade (40 artigos que tratam da utilização de métodos de custeio em hospitais no período de 2004 a 2013) e concluíram que apenas 12 deles utilizavam o método de custeio por absorção e apenas um utilizava o método de custeio ABC.

Além dessas referências e de outras existentes na numerosa literatura sobre apuração de custos e gestão de custos, é conveniente uma breve visão sobre conceito de engenharia e engenharia de custos.

Em Freyre ( 2010) e nos Dicionários Michealis 2000 e Aurélio, encontramos que Engenharia é a arte para aplicação de conhecimentos científicos e empíricos à invenção, aperfeiçoamento de técnicas industriais e certas habilitações específicas à criação de estruturas, dispositivos e processos para converter recursos produtivos em formas adequadas ao atendimento das necessidades humanas. Em Mintzberg ( 2009), encontramos que estratégia é " criar situações para rendas econômicas e encontrar formas de sustentar essas situações' (e) decisões “ determinam a direção geral e sua viabilidade à luz das mudanças previsíveis e imprevisíveis que podem ocorrer em ambientes adjacentes".

O conceito de engenharia de custos é bastante difundido e praticado na construção civil, tendo o Instituto Brasileiro de Engenharia de Custos (IBEC), filiado ao Conselho Internacional de Engenharia de Custos (ICEC), por promotor de técnicas através de cursos de MBA e Pósgraduação para capacitação e consultoria em orçamentação para licitações de obras civis para o setor público. Há dois livros básicos sobre Engenharia de Custos, com essa concepção: o de Paulo Roberto Vilela Dias, disponível no site do IBEC e o de Carvalho e Pini, publicado pela Editora Pini (2012).

Do livro de Carvalho e Pini (2012), destacamos as seguintes acepções para significar este estudo: 1) “ No território dos custos, o conhecimento técnico é capaz de estabelecer as pertinências entre tipologias, metodologias de estudo e valoração e o grau de confiabilidade requerido"; 2) "São produtos da modelagem de custos: matriz de custos; composições de custos unitários caracterizados; e orçamento"; 3) "Na lógica da Engenharia de Custos, a Contingência é a probabilidade de um evento ser impactado ou causar impactos em outros eventos".

Essas referências podem significar a Engenharia de Custos Procedural no âmbito das entidades hospitalares, públicas ou conveniadas ao SUS, e privadas, levando-se em conta a forte probabilidade de contingências de execução, por disfunções logísticas e de produção - que impactam a produtividade, a própria produção de serviços e o consumo dos recursos necessários a essa produção - razão por que é fundamental caracterizar o que será assumido ou destacado na 


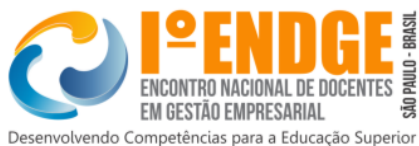

matriz de custos e assumir premissas - que refletem as decisões sobre como fazer e os respectivos coeficientes de consumo - dimensionando-se a capacidade dos recursos de produção.

A Engenharia de Custos Procedural é uma arte de construção do melhor custo e arte é "o conjunto de regras para dizer ou fazer com acerto alguma coisa" (Dicionário Michaelis 2000). Pela sua etimologia, o termo procedural vem de proceder $+u r a+l$; proceder significa começar e prosseguir alguma ação, processo, movimento; procedura significa conjunto ou duração das diversas fases do processo judicial e ura exprime estado, qualidade (Dicionário Michaelis 2000). O termo procedural vem também do domínio cognitivo da taxonomia de Bloom, revisada, que significa " relacionado ao conhecimento de 'como realizar alguma coisa' utilizando métodos, critérios, algoritmos e técnicas" (FERRAZ e BELHOT, 2010). Na concepção deste trabalho, procedural será utilizado como um dos princípios da progressão da complexidade para possibilitar a interpolação de categorias de processos como criar, aplicar, analisar e avaliar, e validar, daí reconhecendo-se sua contribuição para o conhecimento e relevância prática de novo formato e estrutura de design de gestão de custos.

Para fins deste trabalho, Engenharia de Custos Procedural é conceituada como a arte de dirigir a execução prática com acerto de concepções de resultados - nas diversas fases derivadas de um processo de decisões para ações com começo, meio e fim - a partir de simetrias e convergências de conceitos, princípios, ferramentas de métricas interdisciplinares e de normas legais para converter recursos escassos em formas adequadas e produtos e serviços para satisfazer necessidades dos seres vivos (humano, animal, vegetal), através de estruturas que possibilitem rentabilizar a aplicação dos recursos direcionadores de soluções de problemas.

Essa conceituação leva à necessidade da definição e assunção de alguns fundamentos dispostos em normas da Associação Brasileira de Normas Técnicas (ABNT) e da Agência Nacional de Vigilância Sanitária (ANVISA).

No âmbito da ABNT, destacamos a NBR ISO 55.000/2014 que trata de sistemas de gestão de ativos fornecendo uma visão geral para que os requisitos da eficácia e da eficiência possam ser atingidos de forma consistente e sustentável o longo da vida útil dos ativos e, assim, possibilitar a captura, a geração e a entrega de valor com equilíbrio entre custo, risco desempenho e possibilitar a prospecção de oportunidades de melhoria.

No âmbito da ABNT NBR 15.999/2007, destacamos o guia de recomendações de boas práticas de gestão da continuidade de negócios, definindo continuidade de negócios como " a capacidade estratégica e tática da organização de se planejar e responder a incidentes e interrupções de negócios, para conseguir continuar suas operações em um nível aceitável previamente definido" e por gestão da continuidade um processo que identifica ameaças potenciais e seus possíveis impactos nas operações de negócios, nas atividades de valor agregado, caso essas ameaças se concretizem, e estabelece uma estrutura estratégica operacional adequada.

No âmbito da ABNT NBR 15.943/2011, há diretrizes para um programa de gerenciamento de equipamentos de saúde (engenharia da usabilidade) compreendendo um conjunto de ações que visem a garantia da qualidade, assegurando que os equipamentos sejam mantidos, utilizados e controlados com padrões de conformidade apropriados distinguindo os seguintes direcionadores: confiabilidade, disponibilidade, durabilidade; mantenabilidade.

No âmbito da ANVISA, destaca-se a Resolução RDC 02/2010 que trata do gerenciamento de tecnologias em saúde em estabelecimentos de saúde e que define gerenciamento de tecnologias de saúde como o "conjunto de procedimentos de gestão, planejados e implementados a partir de bases científicas e técnicas, normativas e legais, com o objetivo de garantir a rastreabilidade, 


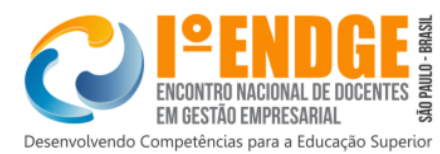

qualidade, eficácia, efetividade, segurança e em alguns casos o desempenho de tecnologias de saúde utilizadas na prestação de serviços de saúde". Isso implica o planejamento e a gestão dos recursos físicos, materiais e humanos com padronização possível de critérios e o registro da forma sistemática de execução das atividades.

Ainda no âmbito da ANVISA, a Resolução RDC 63/2011 estabelece regras para que o hospital desenvolva continuamente uma cultura de cuidados centrados no paciente para humanização da atenção e da gestão em saúde.

A Engenharia de Custos Procedural tem o propósito de tornar simétricos e convergentes os conteúdos, objetivos, regras e "boas práticas" das referências acima desenhando uma estrutura organizacional e de governança, fundamentada e formatada a partir do conceito da "unidade de prática integrada ( UPI)", defendida por Porter e Teisberg ( 2007).

Esses autores defendem a tese "competição baseada em valor para o paciente como soma positiva" e que a estratégia é sair da competição de soma zero nos custos (que guarda certa equivalência com a tese "ganha-perde") para a competição baseada em valor focada em resultados de soma positiva (que guarda certa equivalência com a tese "ganha-ganha"). Em outras palavras, o sistema deve entregar valor ao paciente, no nível onde de fato o valor deve ser gerado ou criado, em cada condição de saúde e em todo o ciclo do atendimento. E por condição de saúde eles entendem como "um conjunto de circunstâncias na saúde de um paciente que se beneficia de um tratamento dedicado e coordenado, (abrangendo) doenças, males, lesões, gravidez, condições co-ocorrentes comuns".

Segundo Porter e Teisberg ( 2007), para estruturar uma unidade de prática integrada (UPI) é preciso que alguns imperativos sejam atendidos, tais como: concentração dos recursos nas áreas em que o prestador se distingue e não apenas esforçando-se para ser bom em tudo; mensurar resultados, experiência, métodos e atributos dos pacientes por unidade de prática; escolha do conjunto de condições de saúde nos quais o prestador é capaz de alcançar excelência em termo de valor ao paciente.

Na concepção da Engenharia de Custos Procedural, a UPI deve ser cocriada explorando-se os princípios da afinidade e da confiabilidade colaborativa para olhar rotinas com olhos de designer para redescobrir nelas objetos inovadores levando cada um colocar a si mesmo em suas criações, num ambiente estimulador para se abrir mão de parte de interesses individuais por benefícios de interesses coletivos: ações sistêmicas de participação, de reconhecimento, de pertencimento. Na UPI as atividades são estruturadas e gerenciadas de modo que produtos e serviços sejam relacionados e congruentes, tendo como referencial básico a eficácia, requerendo, para tanto, o uso eficiente dos recursos para entrega de valor ao paciente, possibilitando rentabilizar as tecnologias em saúde.

Essa é a lógica de execução que reconhece a estrutura da modulação básica de serviços, as relações de precedência e as relações de pertinência para avaliação de fatores culturais que possam interferir, intensificar ou enfraquecer as relações entre fatores clínicos, fatores econômicos e fatores de agência (administração). Assim, a Engenharia de Custos Procedural desenhou o diagrama abaixo configurando uma estrutura de uma unidade de prática integrada (UPI) para entidades hospitalares: 


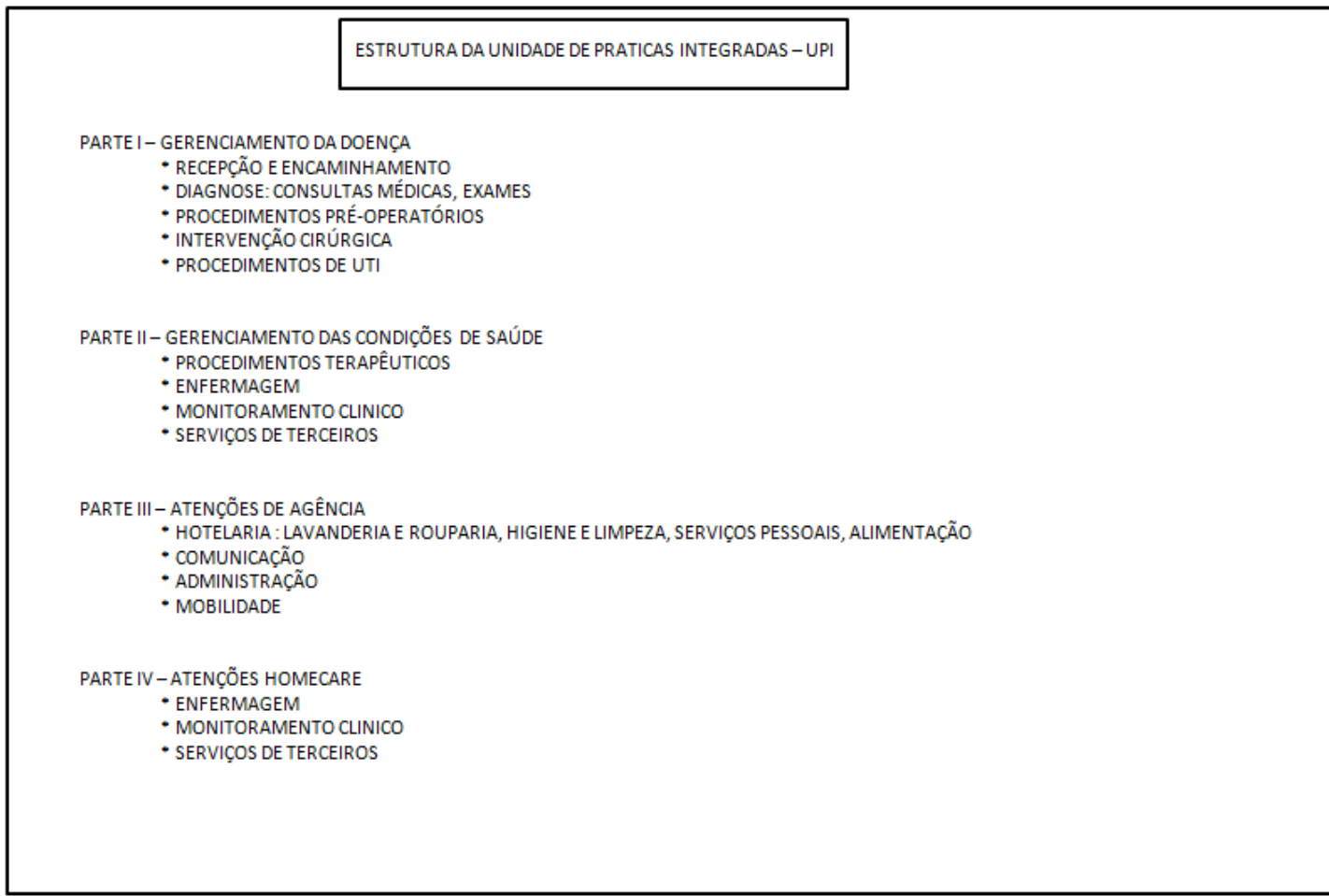

Figura 1 - Estrutura da Unidade

Três variáveis estão implicitamente ligadas nessa estrutura de UPI: volume, tempo e aporte de capital (recursos) e cada parte contém lateralidade e profundidade para gerar um estudo individualizado segundo as dimensões pertinência clínica e pertinência técnica no que dizem respeito a requisitos e atributos para entrega de valor e, consequentemente, seus respectivos aportes de capital necessários e pertinentes. Uma cirurgia, por exemplo, passa pelas Partes da UPI: condição da doença, condição da saúde e atenções de agência.

Na UPI, os eventos são alocadores de aportes de capital com custos de transação, e as principais relações alocadoras de aportes de capital com custos de transação - fluxo de eventos, atos e fatos (alterado por percepções de pessoas que agem em condições diversas e adversas para efetivação da implementação de uma UPI) - são:

- Negociações com pagadores;

- Negociações com fornecedores;

- Negociações com empregados;

- Negociações com o Poder Público;

- Negociações com a sociedade.

Devem ser levados em conta os determinantes de aportes de capital baseados em volume para comportar a capacidade de produção de serviços tais como

- Escala: tamanho dos aportes de capital;

- Escopo: grau de integração da cadeia de valor para os serviços;

- Experiência: grau de experiência acumulada com as tecnologias;

- Tecnologias e complexidade: efetividade nos cuidados aos pacientes;

- Instalações e processos;

- Hora técnica efetiva 
Assim, a Engenharia de Custos Procedural tem por tipologia para segregação de aportes de capital e agregação de dimensões com vistas à precificação dos procedimentos médicohospitalares e seu ajustamento ao custo-máximo, a taxonomia abaixo. Porter e Teisberg ( 2007) homogeneízam todos os procedimentos médico-hospitalares em uma única categoria: condições de saúde. Para a Engenharia de Custos Procedural é conveniente a fixação de três categorias de aportes de capital ( ou custos): condições da doença, condições da saúde e atenções de agência. Essas categorias são divididas em subcategorias de pertinência e estas são categorizadas para incorporação de condições específicas do procedimento clínico-cirúrgico, segundo as diferentes naturezas de contingências advindas de condições críticas de usabilidade de equipamentos, instalações, espaço, pessoal de operação e de apoio ou de disfunções logísticas, de períodos descontínuos de trabalho, de restrições ambientais, sociais e financeiras.

Taxonomia de pertinência para alocação e mensuração dos recursos como aporte de capital: I - Agrupamento dos aportes de capital por condição da doença

1 - De Pertinência Clínica

- Hora-médico

- Hora-anestesista

- Hora-enfermagem

- Serviços de terceiros

- Serviços de diagnósticos

- Serviços outros

- Medicamentos e insumos

○ Descartes

2 - De Pertinência Técnica

- Hora-técnica de equipamentos

- Hora-técnica de instalações

- Hora-técnica de esterilização

- Outros

3 - De Pertinência Econômica

- Depreciação Econômica

- Outros

II - Agrupamento dos aportes de capital por condição da saúde

4 - De Pertinência Clínica

○ Hora-médico

- Hora-anestesista

- Hora-enfermagem

- Serviços de terceiros

- Serviços de diagnósticos

- Serviços outros

- Medicamentos e insumos

- Descartes

5 - De Pertinência Técnica

- Hora-técnica de equipamentos

- Hora-técnica de instalações

- Hora-técnica de esterilização

- Outros

6 - De Pertinência Econômica

○ Depreciação Econômica

- Outros

III - Agrupamento dos aportes de capital por atenções de agência

7 - De Pertinência Diretiva

8 - De Pertinência Organizacional

9 - De Pertinência dos custos dos aportes de capital

10 - De Pertinência Tributária e Normativa 
Como desenvolver uma cultura institucional capaz de implantar e tornar executável essa estrutura de UPI com tal taxonomia?

Primeiramente aprendendo com Peter Senge ( 2003) que o pensamento sistêmico é como a alavanca de Arquimedes, com ele podemos experimentar as consequências de decisões; que nós precisamos de conhecimentos e ferramentas para esclarecer padrões como um todo e ver como modificá-los efetivamente; que os modelos de ver o contexto e de agir implícitos devem ser explicitados, devem ser compartilhados para geração de novas visões e olhar dentro das estruturas subjacentes e adjacentes.

Em segundo lugar lançando mão do conceito e técnica do Business Model Generation (Canvas), desenvolvido por Osterwalder e Pigneur (2011). Esses autores cocriaram com mais de 470 profissionais em mais de 40 países o modelo de gestão de negócios (Canvas) que tem por arquitetura o cérebro humano, principalmente sua estrutura de funcionamento: um lado direito (que responde pelas emoções e comportamento) e um lado esquerdo (que responde pela lógica, razão, cálculos) e que se interligam. O lado direito corresponde a três blocos ou módulos que congregam as atividades discussões sobre segmentação de clientes, sobre o relacionamento com os clientes e sobre os canais e formas de acesso aos clientes. O lado esquerdo congrega três blocos ou módulos que correspondem às atividades relativas a parcerias, a atividades-chave e a propostas de alocação dos recursos necessários.

Esse conjunto de seis blocos, agrupados em dois lados, é interligado por um bloco ou módulo que contempla a proposta de valor a ser criada, gerada e entregue aos clientes. Como base estão dois blocos ou módulos, um que contempla as propostas e discussões a respeito de parâmetros, modelos e ferramentas para mensuração dos custos e despesas e o outro bloco ou módulo que contempla as discussões sobre a definição da precificação, como as fontes de recursos financeiros devem ser aportadas e as propostas de destinação das rendas líquidas (lucros).

O Canvas é uma ferramenta procedural prática e útil que promove entendimento, discussão, criatividade, análise, validação e decisão. Ele requer como premissa pessoas que sejam visionárias, inovadoras e revolucionárias esforçando-se para desafiar os modelos e práticas de gestão de senso comum e projetar empreendimentos de amanhã. Essa premissa ajusta-se aos requisitos da Engenharia de Custos Procedural que adaptou o Quadro Canvas de Osterwalder e Pigneur ( 2011) para a seguinte configuração, apropriada e sensibilizada para a gestão da UPI em um Estabelecimento de Assistência à Saúde (EAS): 
METODOLOGIA PARA ALOCAÇ̃̃o E MENSURAÇÃo

DE APORTES DE CAPITAL DE INVESTIMENTO

EM UMA UPI FUNDAMENTADA NO CANVAS PARA UM EAS

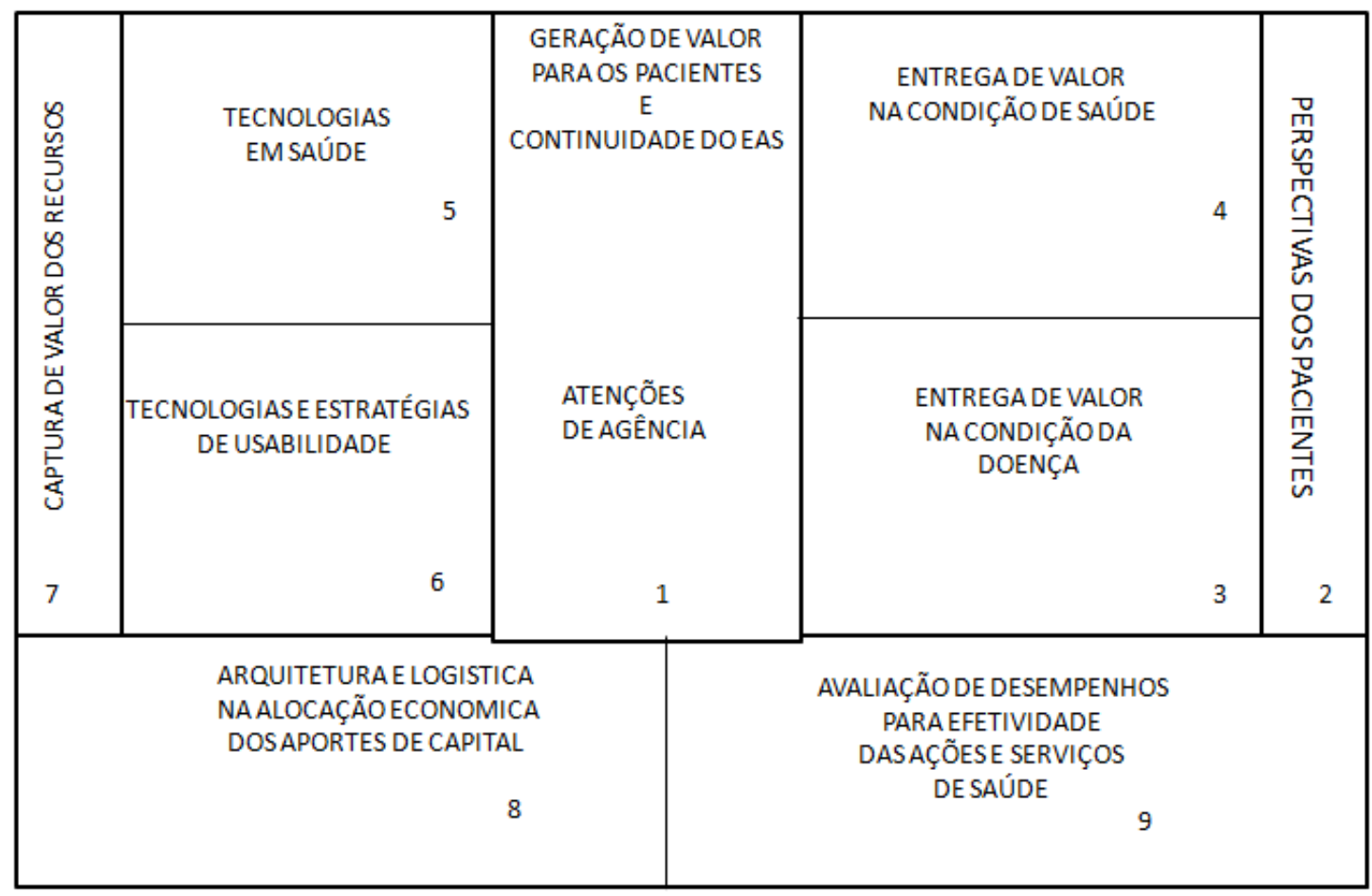

Figura 2 - Mensuração de aportes

Podendo o Canvas ser adotado como ferramenta inovadora e revolucionária para a gestão da UPI, como apropriá-lo e sensibilizá-lo para a gestão de ativos direcionadores de transação de valores - captura, geração, criação e entrega de valor? De ativos simultaneamente consumidores de valor e geradores de valor? Substituindo estruturas estáticas funcionais por estruturas dinâmicas procedurais.

O Design Thinking, desenhado por Liedtka \& Olgivie (2015), na concepção metodológica da Engenharia de Custos Procedurais, pode estabelecer essa passagem ou fazer essa substituição, mediante a conversão, a sincronização, a integração, a consolidação, a validação, a navegabilidade de informações de decisões cocriadas permitindo reestruturações e resiliências necessárias para atender à complexidade da produção de serviços em saúde.

Esse processo começa com uma questão, uma indagação, uma incerteza que precisa chegar a uma solução, a melhor possível. Esses autores mostram isso na imagem de circunvoluções abaixo para despertar a ideia de que não há um processo formal para se navegar nesse emaranhado. 


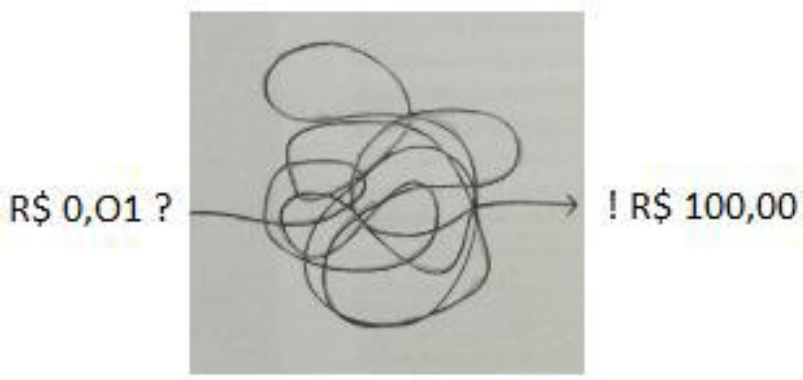

Figura 3 - Apuração 1

Mas pode-se chegar à melhor solução com num processo fluido sistematizando soluções centradas em quatro perguntas, dispostas dentro de abóbadas à semelhança da imagem do DNA: o que é?, e se?, o que surpreende?, o que funciona? Como é mostrado na imagem abaixo:

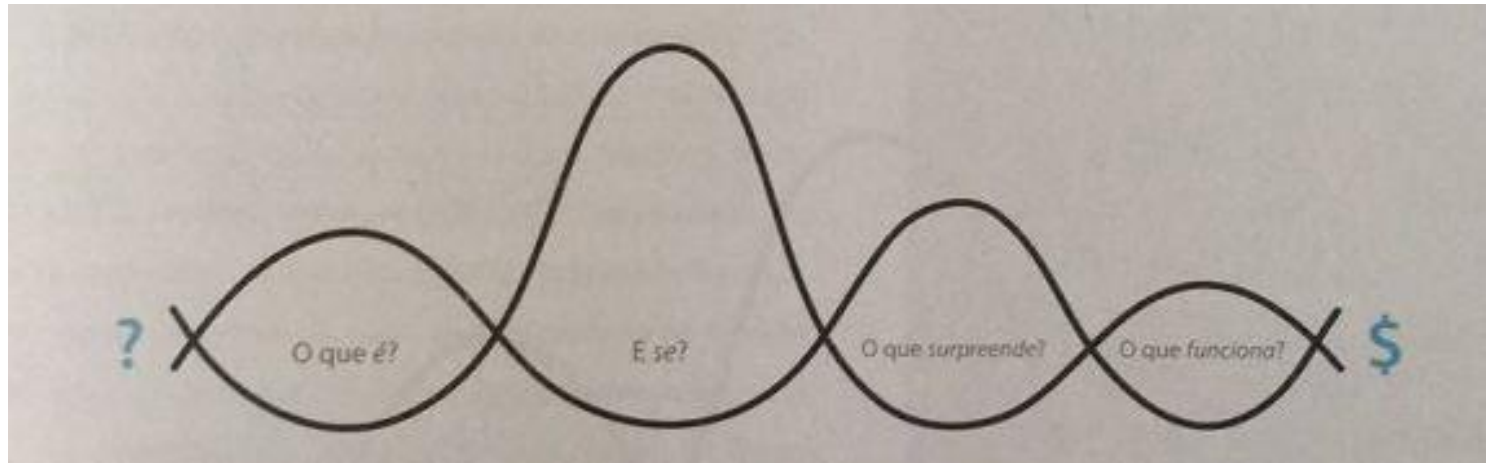

Figura 2 - Apuração 2

Isso significa sair de habituais enquadramentos do problema (conceito da metodologia científica) e sair do conjunto de soluções preexistentes do planejamento estratégico de Porter e do raciocínio mecanicista Druckeriano ( a finalidade da empresa é criar clientes) para cocriação de soluções com o paciente e para o paciente.

A sincronização entre as respostas dessas quatro questões determinará o estabelecimento de critérios de alocação de recursos e a sua respectiva apropriação monetária, por pertinências técnicas e de riscos, categorizada por custos e despesas, por produção e agência, por escopo e escala

A identificação, a classificação e a seleção de métricas requerem uma metodologia de preditividade de requisitos - ações para monitorar a condição de uso de ativos e prever potencial incidente que ocasione interrupções da produção - e de predizibilidade - o grau de probabilidade em que um comportamento na usabilidade de ativos pode ser previsto e rentabilizar ou não direcionadores de solução de problemas.

Para que essa metodologia seja operacionalizada, é necessário o reconhecimento da importância dos requisitos-atributos dos ativos intangíveis e da priorização dos mesmos. Essa operacionalização metodológica que significa sincronizar direcionadores de custos de transação com direcionadores de transação de valores está expressa e formalizada na Figura abaixo: 


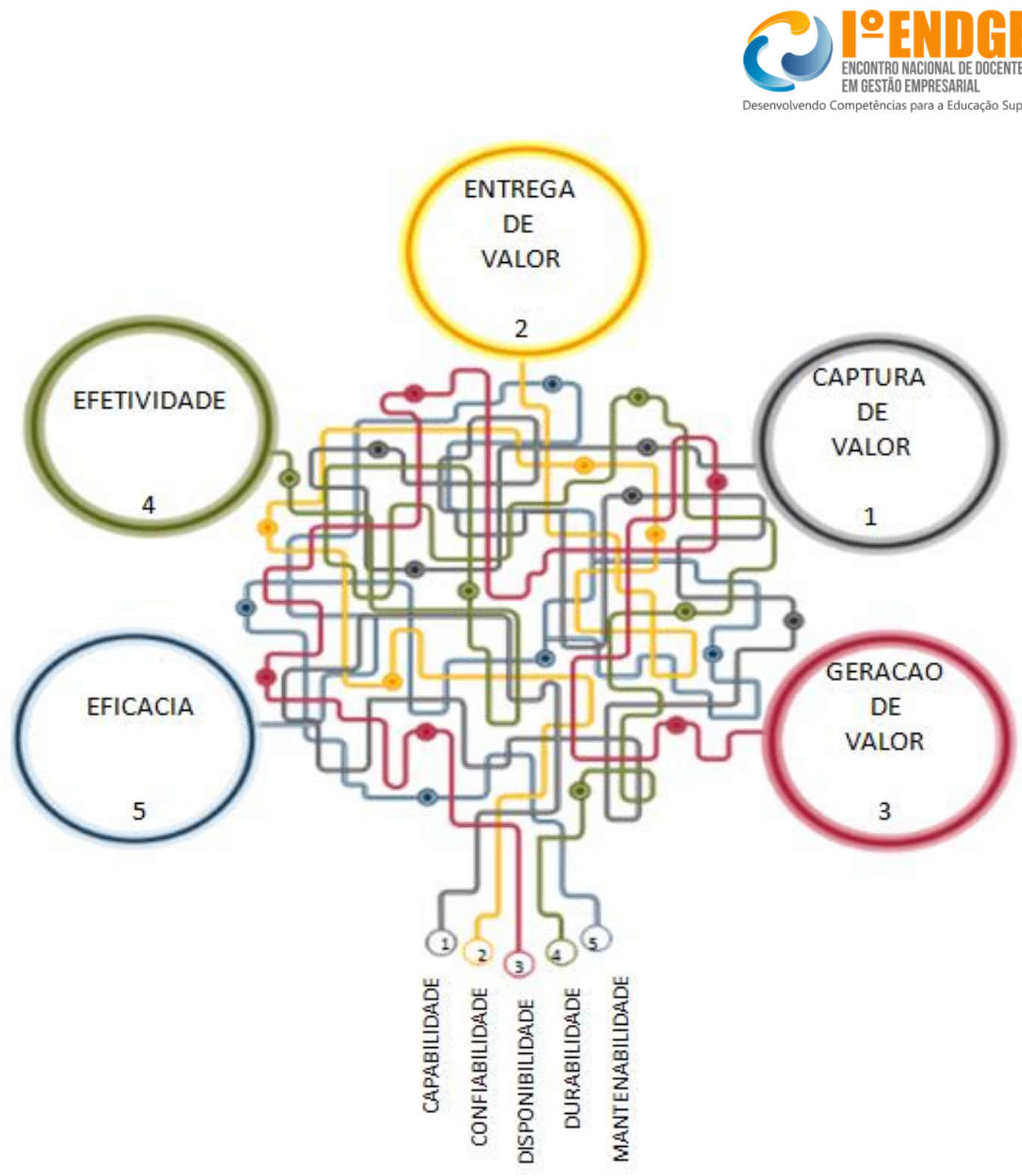

Figura 5 - Direcionadores de transação de valores

Desse aparente emaranhado ou circunvoluções que dão ideia de labirinto, podem-se extrair asserções que se alinham entre si e possibilitam condensá-las nas convergências de simetrias entre as dimensões dos direcionadores de transação de valores, e suas propriedades e atributos, com os indicadores multidimencionais de desempenho.

A conjunção do modelo Canvas com a técnica Design Thinking, como ferramentas para implantação e gestão de uma unidade de prática integrada (UPI), favorece a Engenharia de Custos Procedural desenhar uma tecnologia para se obter o melhor custo, apesar de restrições implícitas na tabela de preços de serviços hospitalares estabelecida pelo SUS. Essa tecnologia está sintetizada na Figura abaixo que se fundamenta na metodologia Backward Analysis. 


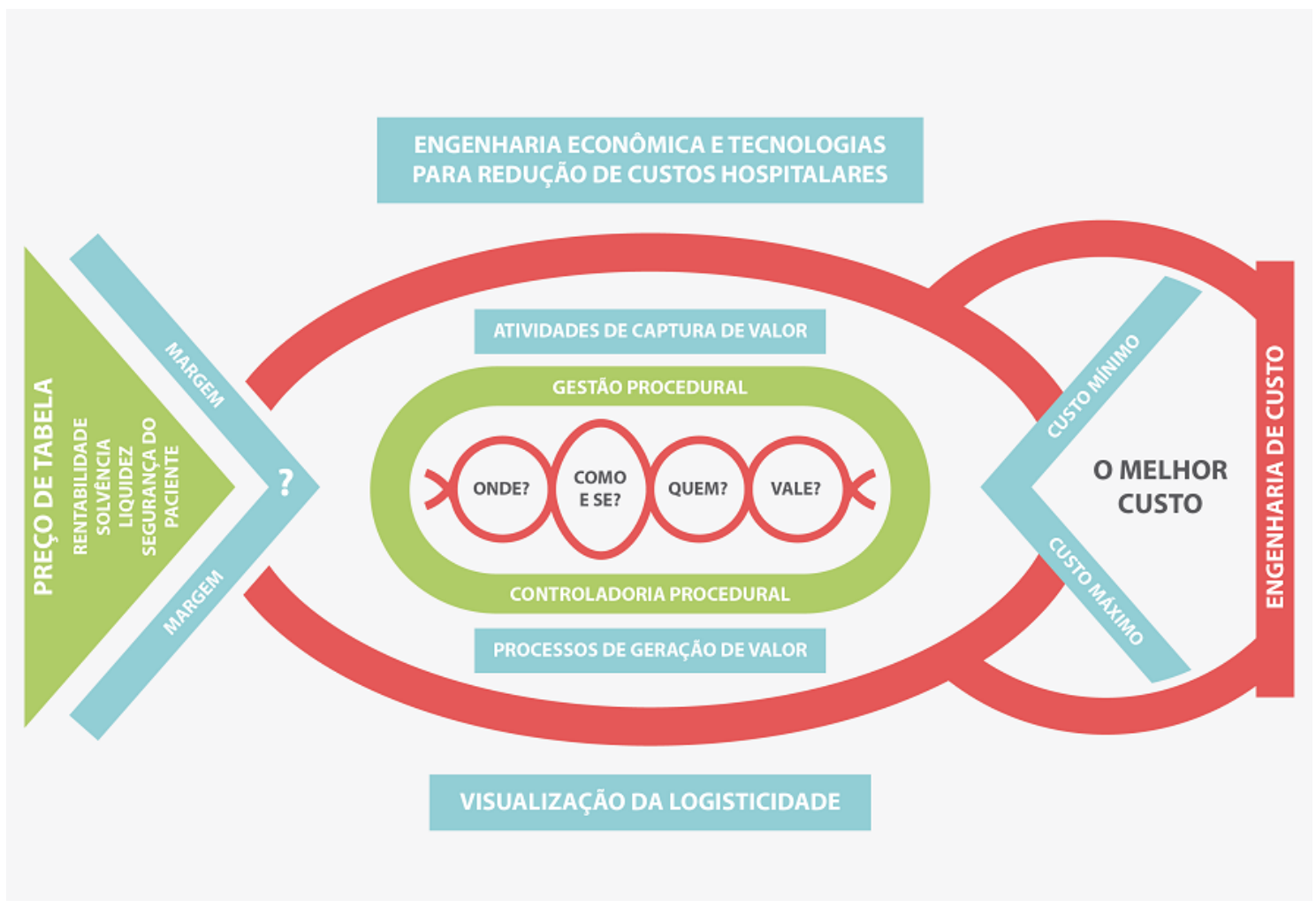

Figura 5 - Proposta integrada

As respostas à questão onde? partem do levantamento de premissas locacionais que poderão dar suporte técnico, jurídico, normativo e financeiro aos coeficientes de consumo dos insumos requeridos para os cuidados de cada paciente em relação à sua patologia.

Em seguida, avança-se no estudo das variações de desempenho dos recursos requeridos em cada procedimento na cadeia da UPI, variações em relação à produtividade, ao consumo de materiais e horas máquina/instalação/espaço e mão de obra, ao consumo de insumos. Isso constitui a fase do Como e Se?

$\mathrm{Na}$ fase seguinte quem?, são discutidas necessidades específicas do paciente, quais os requisitos para satisfazer os atributos dos cuidados ou procedimentos; a qualificação dos executores dos procedimentos; a qualidade dos serviços dos ativos exigidos e sua gestão para procedimentos; a segurança do paciente; a diagramação de sincronias entre requisitos e atributos das patologias e as ofertas ou prescrições do SUS.

Por fim, nos questionamentos vale?, confrontam-se a produtividade média com a produtividade máxima alcançável e o concurso dos parâmetros e coeficientes técnicos, financeiros e humanos para os resultados alcançados.

A sincronização entre as respostas dessas quatro questões determinará o estabelecimento de critérios de alocação de recursos e a sua respectiva apropriação monetária, categorizada por custos e despesas, por produção e agência, por escopo e escala. 


\section{Conclusão}

Há uma grande lacuna entre o que o Ministério da Saúde estabelece para a rede de hospitais conveniados com o SUS, em termos de estímulos para adoção de um processo de modernização gerencial e efetivamente a adoção do PNGC e sua prática através do Apurasus. Algumas experiências com sua implantação resultaram em insucesso.

Diante disso, procurou-se, neste trabalho, desenvolver e colocar para discussão uma tecnologia inovadora e revolucionária, denominada Engenharia de Custos Procedural - que se fundamenta em alguns postulados da engenharia de custos concebida para a construção civil, nas abordagens de gestão de ativos da ABNT e do Business Model Generation (Canvas) e do Design Thinking ( como modelagem da neurogestão) e a modelagem de estrutura organizacional denominada unidade de prática integrada (UPI) para condições da doença e da saúde - para se obter o melhor custo, convergindo o custo máximo com o custo mínimo.

Acredita-se que essa tecnologia procedural pode favorecer a melhoria do PNGC em seu processo de execução, posto que substitui metodologias baseadas em conceitos e práticas contábeis tradicionais por estruturas dinâmicas procedurais. No entanto, é recomendável a Engenharia de Custos Procedural avançar em estudos e pesquisas referentes a estratégias matemáticas para construção, sensibilização e validação do melhor custo.

\section{Referências Bibliográficas}

ANVISA. Assistência Segura: uma reflexão teórica aplicada à prática. GVIMS/GGTESBrasília: 2013

BERTÓ, Dalvio José; BEULKE, Rolando. Gestão de custos e resultado na saúde: hospitais, clínicas, laboratórios e congêneres. $5^{\text {a }}$.ed.-São Paulo: Saraiva, 2012

CARVALHO, Luiz Raymundo Freire de; PINI, Mário Sérgio. Elementos de Engenharia de Custos: desatando o nó para os agentes de obras públicas na formação do preço para a construção civil. São Paulo: PINI, 2012.

DIAS, Paulo Roberto Vilela. Engenharia de Custos: uma metodologia de orçamentação para obras civis. 10a . Ed.-1950. WWW.ibec.org.br/publicações.

FERRAZ, Ana Paula do Carmo Marcheti; BELHOT, Renato Viro. Taxonomia de Bloom: revisão teórica e apresentação das adequações do instrumento para definição de objetivos instrucionais. Revista Gestão da Produção. São Carlos, v. 17, n.2, p.421-431, 2010.

FREYRE, Gilberto. Homens, Engenharias e Rumos Sociais. São Paulo: É Realizações Editora, 2010.

LIEDRKA, Jeanne; OLGIVIE, Tim. A magia do design thinkink: um kit de ferramentas para o crescimento rápido da sua empresa. São Paulo: HSM Editora, 2015.

$\begin{array}{lllll}\text { MAGALHÃES, } & \text { Nagat } & \text { Faiz } & \text { Ahmad } & \text { Amorim. }\end{array}$ WWW.socialiris.org/ivcongressocq/materiais/CRO2.pdf

MARTINS, Daiana Bragueto, PORTULHAK, Henrique, VOESE, Simone Bernardes. Gestão de custos: um diagnóstico em hospitais universitários federais. WWW.academai.edu/14078547

MINTZBERG, Henry; LAMPEL, Joseph; QUINN, James Brian; GHOSHAL, Sumantra. O processo da estratégia: conceitos, contextos casos selecionados. 4a.ed.-Porto Alegre: Bookman, 2006

OSTERWALDER, Alexander; PIGNEUR, Yves. Business Model Generation - Inovação em Modelos de Negócios: um manual para visionários, inovadores e revolucionários. Rio de Janeiro: Alta Books, 2011. 


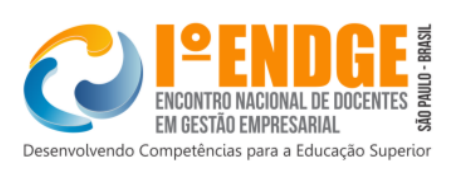

PORTER, Michael E.; TEISBERG, Elizabth Olmsted. Repensando a saúde: estratégias para melhorar a qualidade reduzir os custos. Porto Alegre: Bookman, 2007.

SENGE, Peter M. A quinta disciplina, 15ª . Ed.- São Paulo: Editora Best Seller, 2003.

TEIXEIRA, Ana Paula Leal. A Gestão de custos de serviços hospitalares no INCA - avanços e retrocessos para implementação do sistema de apuração de custos. Dissertação para ENSP/FIOCRUZ 2013. Teixeiraaplm pngc dissertação.pdf

www.ibec.org.br

www.icoste.org 